\title{
On Management of Translation Project from the Perspective of Eco-Translatology
}

\author{
Churan Su and Hongmei Ruan
}

\begin{abstract}
This article discusses the management process of a translation project based on computer-aided translation (CAT) software from the perspective of Eco-translatology. The article observes the initiating, planning, implementing and closing of a translation project and analyses how the components of a translational ecology make "adaption and selection", thus achieving internal harmoniousness and ecological balance in an interactional circumstance. The writer hopes to provide people who ran a translation project with advice to do project planning, task assignment and personnel allocation more effectively.
\end{abstract}

Index Terms-Eco-translatology, project management, computer-aided translation.

\section{INTRODUCTION}

Eco-translatology is a translation study based on ecological view. From the perspective of eco-translatology, "translation is a selection when translators adapt to translational eco-environments and then transplant texts (from one language to another)" [1]. It is on the basis of "adaption/selection" theory. It also compares translational ecology with natural ecology, and discusses the relations between translational eco-environments, translation texts and translation communities, then makes a study of translatology (macro view), translation theories (mid-scale view) and translation texts (micro view) [2].

Eco-translatology defines that: translation is a unified and harmonious system [1]. In this system, all components coexist and rely on each other. This concept is similar to a management system of a translation project. Only if members of translation projects, texts to be translated and project managers formulate a harmonious union, projects can run successfully. Meanwhile, nowadays more and more cases use CAT in the management of translation projects. Therefore, this article will take computer-aided translation projects as an example to study how translational eco-environments, translation texts and translators interact with each other and make the whole "unit" run harmoniously from the perspective of eco-translatology.

Before a translation project initiates, a project manager (or director) needs to contact with a client and know his or her demand. After that, he has to convene a meeting for group members to determine the completion time of a task. This is actually the forming of a translational ecosystem in the project. The manager has to be responsible for adjusting the balance of this system. Later, when receiving an original text, the

Manuscript received March 9, 2016; revised June 15, 2016.

The authors are with Northwestern Polytechnical University, Xi'an City, China (e-mail: willowsu@foxmail.com,ruanhm@nwpu.edu.cn). manager will receive a term base from the client (or establish a new one) and send it with other files together in a package to all project members [3], so the task is delivered. In this process, the manager observes the transmission principle between source language ecology and target language ecology. Then he defines the source text type and makes translation strategies according to the requirements of the client or final readers. Last, for the translators, they have to adapt to the change of the translational eco-environment and choose proper translation strategies and skills. "Natural selection assures the survival of the fittest" (Darwin) [4]. Translators choose right strategies is for "survival". Like the probability of survival of communities is larger than that of individuals in an ecological system, the forming of a translation project group increases the chances of "survival" of group members. Usually they only need to fit in an ecological system inside a project and coexist with each translation steps (see Fig. 1).

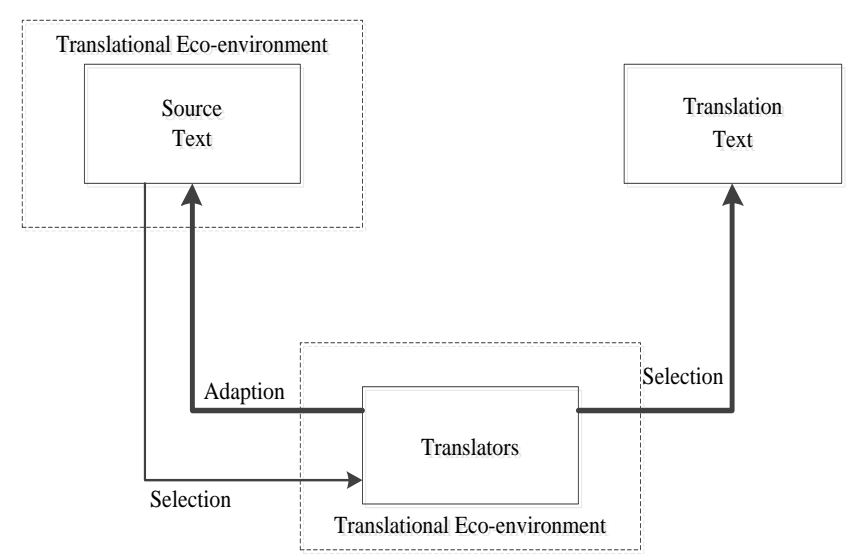

Fig. 1. "Adaption/Selection" of translators [1].

This article discusses ecological systems inside translation projects, "lives" of texts and "survival" of translators. Also, it observes task allocation and procedures of translation projects. It hopes to provide suggestions to future project management.

\section{INITIATING AND PlanNing OF A TRANSLATION PROJECT AND ESTABLISHMENT OF A TRANSLATIONAL ECOSYSTEM}

The initiating of a translation project usually contains three stages-analyzing, assessing and acquiring. First of all, a project manager has to be familiar with his client's information, figure out the goal of this project and communicates with the client regularly. Then, he should define the complexity of this project and feedback the difficulties to the client. At last he should be able to make a cost evaluation of the whole project. After acquiring the 
project, it has to be further analyzed so that feasible principles can be made after that [5].

When the project initiates, the manager ought to collect related information and data [6]. Information processing software such as Microsoft Project Server can be used to sort out and analyze the collected information. After the project frame is formed, the manager could divide the whole project into individual tasks according to WBS (Work Breakdown Structure) template so that he can directly supervise every individual task of the project. If there is no existing template, he can still set up a new one according to requirements of different projects. Afterwards, translators in different areas of expertise are selected in accordance with different projects [7] (see Fig. 2 and Fig. 3).

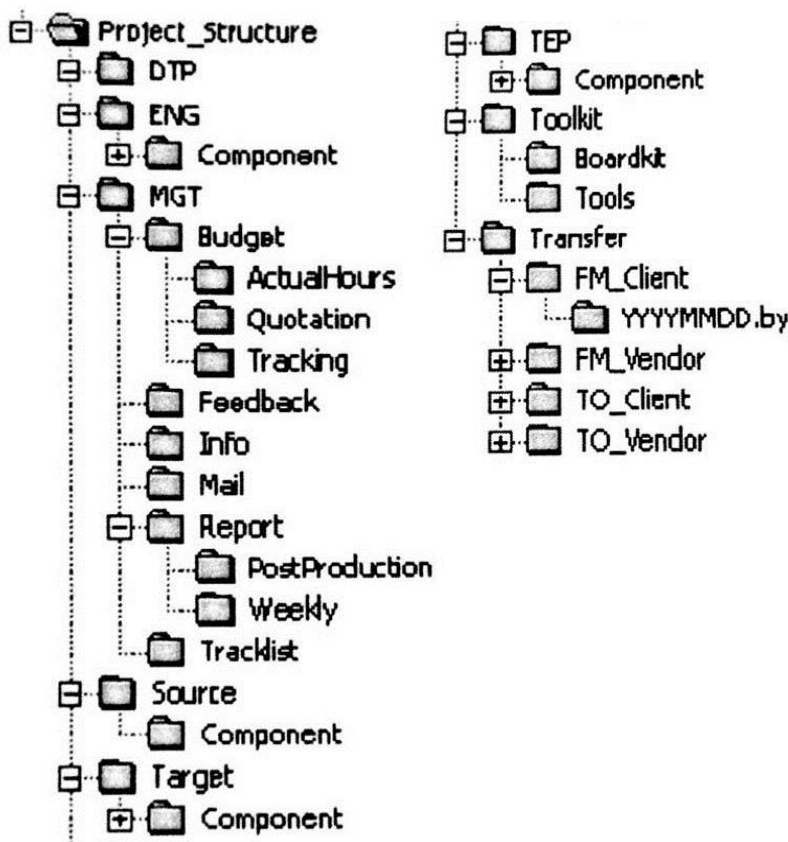

Fig. 2. File structure of translation project management.

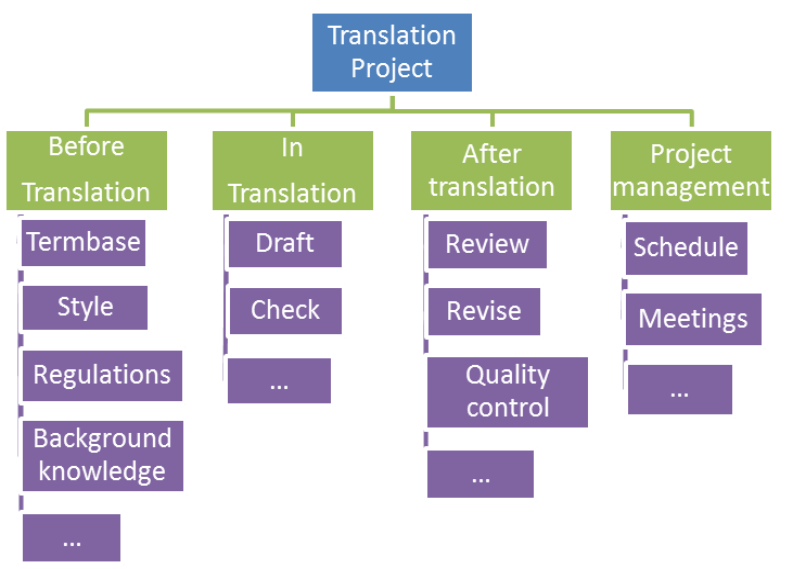

Fig. 3. A WBS template of the translation project.

Now a translational ecosystem has been completed. It consists of a project manager, translators, texts and a client, which interact with each other inside this system; and this ecological system also interacts with other different systems (e.g. translation market).

For a CAT project which applies SDL Trados, the translational ecosystem forms when the file package has been established and delivered. First, the manager receives files from the client, then uses WBS template to divide the whole task into individual packs and sends them to all group members. When the translators open the file package by SDL Trados, they can get the term bases, the translation memories (TM) provided by the client, a task deadline, the client's requirements... This is the forming of the translational ecosystem of this project. In this system, each subject "interacts and (sometimes) overlaps with each other" [1]. For instance, the project manager is in charge of the translators. However, the manager also has to provide the translators with services and meet their requirements while supervising them [8]. Another example is the relation between the project group and the client. The group provides the client with translation service, and the client should provide term bases (if needed) and clarify his demands [9]. The translators are not only managed objects inside the group, but also servants for the client outside the group. The multiple identities of them embody the complexity of the translational ecosystem [10].

\section{IMPLEMENTING OF A TRANSLATION PROJECT AND ADJUSTMENT OF A TRANSLATIONAL ECOSYSTEM}

During the implementing stage of a translation project, an ecological system has already been formed [6]. However, every subject differs from each other. These differences make them adjust their roles so that they can adapt to the translational eco-environment of the project [1], and maintain the balance of this system. Under this balanced circumstance, each subject is mutually beneficial to each other. On the one hand, a good ecology of translation management guarantees that translators can work smoothly. On the other hand, good translators can also promote the development of the whole industry of translation management. In a translation project, the manger is of a core status. He needs to track and supervise each task, contact with his client in time to solve problems and make sure that every task can be complemented before its deadline. On the contrary, translators' dominant role is weakened. They have to meet the client's demand and adjust their translation strategies in time. Those who cannot adjust themselves quickly will be under the risk of elimination. This is similar to the natural principle of "Natural selection assures the survival of the fittest".

As mentioned above, in a translation project, balances exist between a translator and a translator as well as the translators and the translational ecosystem. In Hu Gengshen's theory, he emphasizes the dominant role of translators during adaption and selection, i.e., translators should adapt to the translational ecosystem and make choices of texts [1]. However, in a translation project, the translational eco-environment restricts translators' activities, so the dominant role of them embodies in their adaption strategies. Starting from the startup meeting, translators begin to make adjustment to the translational ecosystem of the project. Who are the readers? What is the purpose of translation? The information is given at very beginning by the client, so the translators need to adapt to the translational eco-environment under certain restrictions and produce translation texts which accord with the requirement. Second, translation software usually provides translators with 
term bases and translation memories, so the subjective initiative of them will be restricted [11]. Last, the translators in a same group have to obey the instructions of the project manager, accept the intensity of the task and struggle to meet the deadline. According to these restrictions, the adaption and selection of translators in a project will be a long and dynamic process.

\section{Closing OF A TRANSLATION PROJECT AND CONCLUSION OF A TRANSLATIONAL ECOSYSTEM}

The closing of a translation project includes reviewing, collecting feedback and summarizing the project [6]. Now the translational eco-environment of the project is almost stable and the translational ecology is improved through practice. The translational ecosystem is going to finish the task as long as the conclusion part is done. Also, it can be used for reference when establishing similar translational ecosystems.

In a CAT project which applies SDL Trados, when translators finish their tasks in a stable translational eco-environment, the closing part will be regarded as reviewing and reporting steps. From the perspective of eco-translatology, this stage discusses the function of a "Translation Community" (translators, reviewers and the project manager) a lot [12] (see Fig. 4).

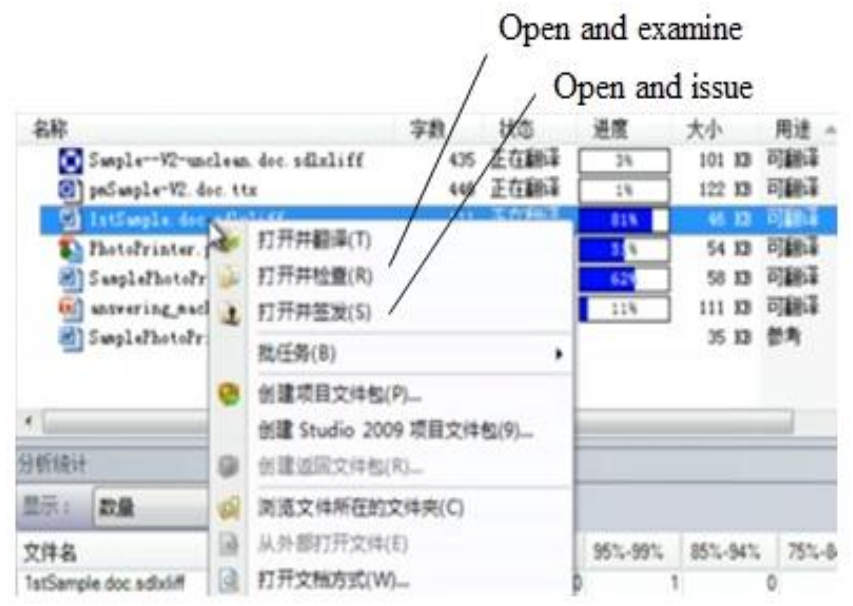

Fig. 4. The edit page of a translation text.

For example, when the translation has been completed, the reviewers using SDL Trados could click "Open and review" button to check the translation text. After that, the manager could click "Open and issue" button to do the second round checking of the text, thus guaranteeing the text quality. During the reviewing, they can add explanation ("Comment") for each reviewed sentence and summarize them into a translation report for the client's reference. When the translation text has been sent to the client, the project group has to wait for feedback so that they can make further amendments to the text. After that, a closing meeting will be held between the manager, the translators and the liaison man. Last, they will complete a final report and archive all the files for future reference and use [6]. In short, using CAT tools is a mechanical way of doing translation, but reviewing and concluding part pays more attention to humans' function. Therefore, it can be seen that the dominant role of the translation community is enhanced in the final stage.

\section{CONCLUSION}

In a translational ecosystemto which a CAT software-based project belongs, a translation text, a project manager, translators, reviewers and a client always interact with each other. To reach the balance of the system, they need to keep making adjustments to the translational eco-environment. The manager has to formulate certain rules according to the requirement from the client. Also, he has to guide the translators to make "adaption and selection" inside the translational eco-environment and promote mutualism between each subject. This conforms to the concept of making the full use of a translation community in eco-translatology.

Through the analysis of each stage of a translation project, the functions of all subjects are overlapped sometimes; the "adaption and selection" of the translational eco-environment is a dynamic and long-lasting activity; the dominant role of each subject of a translation community is not weakened even in the closing part of a project. Software like SDL Trados connects subjects of a translational ecosystem through accepting an integrated translation package and establishing shared term bases. A close circle is formed in a project and thus an orderly operation of a translational ecosystem can be realized.

\section{ACKNOWLEDGMENT}

I would like to sincerely thank my advisor, Hongmei Ruan, who kept giving me good advice during my postgraduate years and who kept inspiring me when I stuck in bottlenecks. I would also like to thank all the other professors and associate professors who helped me though my specialist courses. Without their help I could not systematically collect knowledge from that and finish this paper.

Northwestern Polytechnical University provided me with a good academic circumstance. The School of Foreign Language of NPU supported me to attend academic seminars. My classmates and friends encouraged me in my study. I am especially thankful to that.

\section{REFERENCES}

[1] G. S. Hu, Eco-Translatology: Construction and Interpretation, Beijing: The Commercial Press, 2013, p. 39, 46, 51, 80.

[2] G. S. Hu, "Eco-features of eco-translatology and the implications to translation studies," Foreign Languages in China, vol. 8, no. 6, pp. 96-99, 109, Nov. 2011.

[3] L. Bowker, Computer-Aided Translation Technology: A Practical Introduction, Ottawa: University of Ottawa Press, 2002, p. 77.

[4] S. Hugs, "R\&D report of eco-translatology: Ten years' research, ten years' progress," Shanghai Journal of Translators, no. 4, pp. 1-6, 2011.

[5] Project Management Institute, A Guide to the Project Management Body of Knowledge, Newton Square, Pennsylvania, USA, 2013.

[6] H. W. Wang and H. S. Wang, A Practical Guide to Translation Project Management, Beijing: China Translation \& Publishing Corporation, 2013, pp. 15, 44-52, 57-66.

[7] C. Y. Wang, L. L. Yan, and Y. L. Zhang, "Translation project management and professional translators training," Chinese Translators Journal, no. 1, pp. 55-59, 2011.

[8] X. L. Liu, "Ensuring sustainable development of china's translation industry through regulatory measures: Possible solutions to the problems currently besetting China's translation industry," Chinese Translators Journal, vol. 27, no. 4, pp. 5-7, July 2006. 
[9] Q. L. Cui, "A study on language property of enterprises and platform establishment," Shanghai Journal of Translators, no. 6, pp. 64-67, 2012.

[10] G. S. Hu, "Translational ecology vs. natural ecology: Relevance, similarity and isomorphism," Shanghai Journal of Translators, no. 4, pp. $1-5,2010$.

[11] H. W. Wang and Z. Zhang, "A study on terminology management in translation projects," Shanghai Journal of Translators, no. 4, pp. 64-69, 2014.

[12] N. Wang, "Eco-literature and eco-translatology: Deconstruction and reconstruction," Chinese Translators Journal, no. 2, pp. 10-15, 95, 2011.

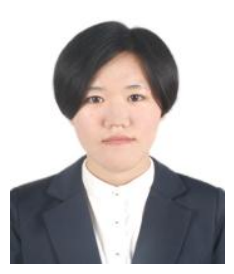

Churan Su was born in Yichang, Hubei, China on December 20, 1991, she is a postgraduate of the School of Foreign Language of Northwestern Polytechnical University (NPU), majoring in translation. She obtained her bachelor degree of arts in the School of Foreign Language of NPU, Xi'an, China in 2014.

She has published a paper "A Look at the Translation of Public Signs in the Scenic Spots of Yichang" (Wuhan, China: English Square, 2014). She was invited to attend the $5^{\text {th }}$ International Symposium on Eco-translatology in June 2015.

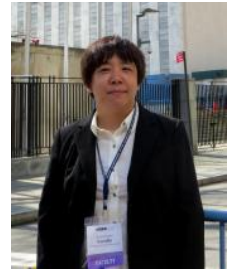

Hongmei Ruan was born in Beijing, China on December 17, 1965, she is a professor of the School of Foreign Language of Northwestern Polytechnical University (NPU). She obtained her doctorate of English language and literature in Shanghai International Studies University, Shanghai, China in 2014, master degree of arts in Xi'an International Studies University, Xi'an, China in 1990; and bachelor degree of arts in Xi'an International Studies University, Xi'an, China in 1987.

She is the director of the MTI Education Center of NPU and the head of the Department of Foreign Languages of NPU Ming De College, in Xi'an, China. She has published some papers, "Deconstructionism in Translation Through New Versions of Idioms," Journal of Northwest University (Philosophy and Social Sciences Edition), 2007, "A Deconstructive Study of the English Translation of Chinese Poems," Journal of Lanzhou University (Social Sciences), 2008, and "Back to Historical Contexts - A Rethink of Studies on Traditional Chinese Translation Theories," Journal of Socialist Theory Guide, 2009.

Prof. Ruan is a member of United Nations Association of China, a member of Shaanxi Translation Association, a committee member of the School of Foreign Studies Degrees Section of Xi'an Jiaotong University and the first chairperson on duty of the Joint Committee of Model United Nations of Chinese Universities. 